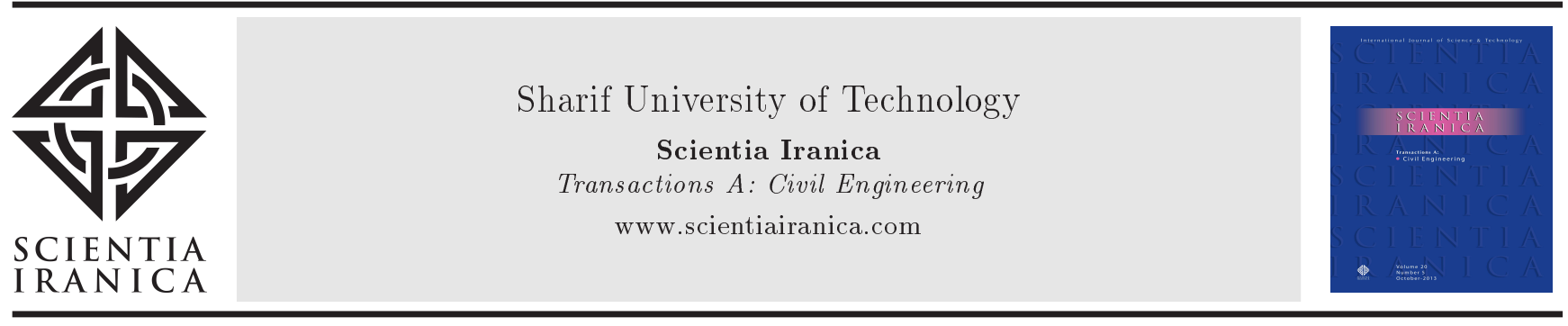

\title{
Optimization of hedging rules for hydropower reservoir operation
}

\author{
K. Sasireka ${ }^{\mathrm{a}, *}$ and T.R. Neelakantan ${ }^{\mathrm{b}, 1}$ \\ a. School of Civil Engineering, SASTRA University, Thanjavur 613401, India. \\ b. Centre for Advanced Research in Environment, School of Civil Engineering, SASTRA University, Thanjavur, 613401, India. \\ Received 22 September 2015; received in revised form 30 December 2015; accepted 30 May 2016
}

\author{
KEYWORDS \\ Hedging rule; \\ Reservoir operation; \\ Hydropower; \\ Optimization; \\ Genetic algorithm; \\ Artificial bee colony \\ algorithm; \\ Imperialistic \\ competitive \\ algorithm.
}

\begin{abstract}
Reservoir operation plays an important role in economic development of a region. Hedging operations were used for municipal, industrial, and irrigation water supplies from reservoirs in the past. However, hedging operation for hydropower reservoir operation is very rare. A practically simple and useful new form of Standard Operation Policy and a new form of hedging rules for hydropower production are introduced in this paper and demonstrated with a case study for hydropower reservoir operation of Indirasagar reservoir system in India. The performance of optimal hedging rules is compared with that of a new standard operation policies and the superiority (reliability increases by about 10\%) of the hedging rules is demonstrated. When the number of decision variables is increased from 5 to 15 , energy production increases by $0.7 \%$, the spill is reduced by $16.8 \%$, and reliability slightly decreases by $2.1 \%$. A bi-level simulation-optimization algorithm is used for optimizing the hedging rules. For optimization, Genetic Algorithm, artificial bee colony algorithm, and imperialistic competitive algorithms are utilized. The results indicate that all the three algorithms are competitive and artificial bee colony algorithm is marginally better than the other two.
\end{abstract}

(C) 2017 Sharif University of Technology. All rights reserved.

\section{Introduction}

In a deficit prone system, availability of water from natural river flow is not reliable as the flow is variable. Hence, reservoirs are used to store river water for later use. The objective of reservoir operation is to improve reliability of water supply by efficient operation during normal and drought situations. Reservoir operation is based on certain rules, which attempt to achieve ob-

1. Present address: Department of Civil Engineering, Kalasalingam Academy of Research and Education, Kalasalingam University, Krishnankoil 626126, India.

*. Corresponding author. Tel. +91 9842634831; Fax: +914362 264120

E-mail addresses: sasireka@civil.sastra.edu (K. Sasireka); neelakantan@klu.ac.in (T.R. Neelakantan) jectives, and finding optimal reservoir operation rules is an important research area. Monitory benefits can be observed in measuring the performance of operation rules. However, often converting the intangible benefits like equivity or environmental protection into monitory terms is difficult. Hence, release based statistics are used to measure the performance. Hedging rule for reservoir operation is inspired from hedging application in financial management. It considers preservation of some water to meet future demands. It increases water availability in the reservoir by accepting small current deficits and avoids unacceptable large deficits in future. It distributes the deficit magnitude across time to minimize the impact of larger shortage. Thus, hedging provides insurance for high-value water uses wherever reservoirs have low refill potentials or experience highly unpredictable inflows [1].

Some of the different forms of hedging rules pro- 
posed for reservoir operation include two-point linear hedging rule [2], one-point hedging rule [3], threepoint linear hedging rule $[4,5]$, discrete phased hedging rules $[3,6,7]$, multi-period ahead hedging rule [8], and type II two-point hedging rule [9]. The historical development of hedging rules for reservoir operation is discussed in the next section.

\subsection{Hedging rules for reservoir operation}

Bower et al. [10] introduced the concept of hedging rule and, after a gap of two decades, Hashimoto et al. [11] explained that the hedging rules were more suitable when the loss function was non-linear. Moy et al. [12] demonstrated that a single-period severe shortage caused more damage than a few smaller shortages spread in time that amounted to the same total shortage when added. Effects of hedging with an explicit demand-management policy based operation of reservoir using the hedging rule were first studied by Bayazit and Unal [2] through stochastic simulation analysis and were further extended by Srinivasan and Philipose [4,5]. Though the hedging rule concept was known earlier, its first application to a field problem was reported in 1994. Shih and ReVelle [3] proposed a continuous linear hedging rule and formulated a non-linear non-separable mixed-integer programming model for a water supply system having 36-month critical period to reduce the maximum shortage and they demonstrated the discrete phased hedging rules. They further modified the formulation to maximize the number of months during which no allocation was required [13]. A longer data sequence of 25 years of monthly data was used by Neelakantan and Pundarikanthan [6,7] for minimizing the sum of the squared deficits of a multi-reservoir water supply system through a discrete phased hedging policy.

By modifying a linear model into a quadratic model, Tu et al. [14] showed improved results through discrete phased hedging rules for a multi-purpose multireservoir system. Several hedging rules, with various lead-time and reduction percentages, were developed to investigate the effects on shortage characteristics. Reis et al. [15] developed a reservoir operation model and solved the problem by hybrid model of GA and linear programming to determine operational decisions. From their results, it was understood that the model was well suited for generating operating policy in the form of hedging rules without a prior imposition of their form. Shiau [16] analyzed a reservoir that served for both urban and agricultural demands. The definition for the reservoir index, which may be well stated as the probability that the summation of reservoir storage and inflow is sufficient to meet the demand, was used to trigger the hedging as well as to find a hedging factor [16]. Several hedging rules, with various leadtime and reduction percentages, were developed to investigate the effects on shortage characteristics. Subsequently, Shiau and Lee [17] simultaneously minimized the maximum monthly deficit and 'deficit to demand ratio' over the analysis horizon to derive optimal 2point hedging rules by employing a compromise programming based method.

Karamouz and Araghinejad [18] adopted a discrete phased hedging rule for a reservoir system that supplied water for municipal, industrial, and irrigation demands. Shiau [8] introduced the multi-period ahead hedging rule and applied the same for a reservoir system serving domestic and agricultural demands. The effect of spill and evaporation while applying the hedging rules was studied by Celeste and Billib [19]. They found that preserving water before drought should be judged carefully, especially in the regions where the evaporation rate was high. Karamouz et al. [20] applied hedging based optimization model to a reservoir, which served domestic, industrial, and irrigation demands. They obtained hedging rules based on precipitation, temperature, and generated stream flow. Recent attempts were made by Zeng et al. [21] for applying hedging rules for hydropower reservoir operation. They used 'energy available' on the $x$-axis and 'current generation' on the $y$-axis.

\section{Hedging rules for hydropower reservoir operation}

From the above listed literature, it is evident that hedging rules have been applied for domestic, industrial, and irrigation water supplies. The benefit of these cases is a function of water flowrate. However, in the case of hydropower generation, the benefit is a function of product of head of water and flowrate. Hence, the hedging rules used for other purposes cannot be directly used for hydropower reservoir operation.

The power generation $(P)$ from hydropower reservoir is directly proportional to both flowrate $(Q)$ and available head $(H)$ at the turbine $(P \propto Q H)$. The relationship between head and storage available in the reservoir is non-linear. If the water availability in a reservoir is more, the head availability is also more. Hence, for a given quantity of power generation, when the water availability in a reservoir is less, more discharge is required. Thus, for a given power generation, water demand is a function of available storage. However, water demand in the case of domestic, industrial, or irrigation water supply is not dependent on available water in the reservoir. According to the hedging rules developed for the operation of domestic, industrial, or irrigation water supply reservoir, water release depends on available water alone (since the water demand is taken as a constant for a given period) and, hence, in the graphical form, 'available water' is taken on $x$ axis and 'release' is taken on $y$-axis. In other words, 

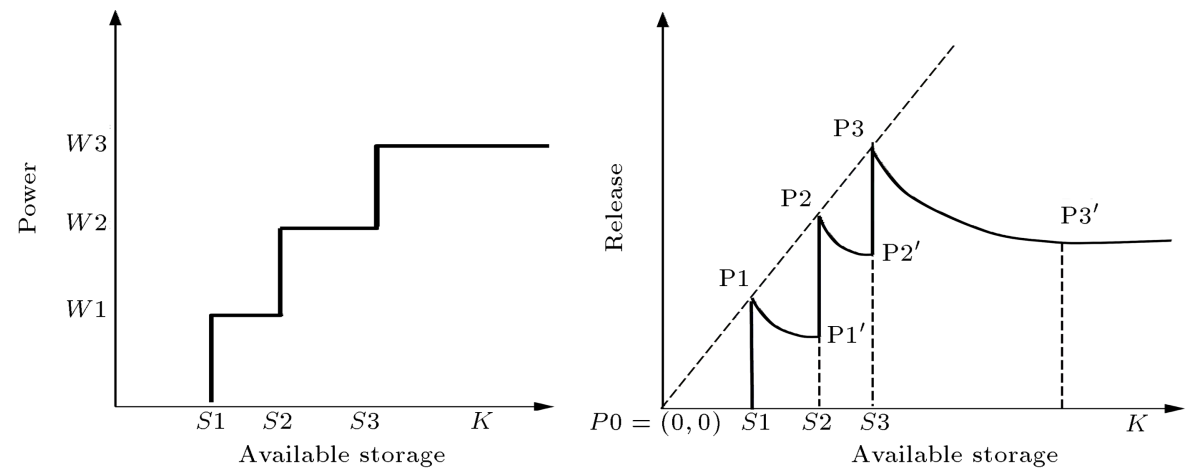

Figure 1. Operation rules for hydropower production in two different forms.

water demand to domestic, industrial, or irrigation water supply reservoir is a fixed value in a given period. However, in the case of hydropower reservoir, water demand is not constant; but, power demand is constant. Hence, the rules with 'storage available' on $x$-axis and 'power production' on $y$-axis are similar to the operation rules applied for municipal water supply (Figure 1). Hence, the operation rules may be presented in the graphical form with 'power generation possible' (based on releasing all the available water or the turbine capacity whichever is less) on $x$-axis and 'power generation' (suggested as per the rule) on $y$-axis. However, providing the rule with 'storage available' on $x$-axis and 'release of water' on $y$-axis is more readable.

Hydropower systems generally have more than one turbine. When water availability is less and power generation is to be partial, either the turbines may be partially loaded or few of the turbines may be fully loaded while the others are not operated. Operating a limited number of turbines may be efficient in many practical situations. In this research work, one such system is demonstrated. Assume there are three similar turbines connected to a reservoir and if the available water is equal to $S 1$, one of the turbines can be operated with its full production capacity; if the available water is equal to $S 2$, two of the turbines can be operated with their full production capacity. However, if water availability is more than $S 1$ but less than $S 2$, only one turbine will be operated with its full production capacity and the remaining water will be used for future power production. When the available water is $S 1$, releasing all the water will produce $33 \%$ of the power generation capacity. Similarly, $S 2$ and $S 3$ at their corresponding availability will produce $67 \%$ and $100 \%$ of the power generation capacity.

In Figure 1, the straight line connecting the points P0, P1, P2, and P3 makes an angle of $45^{\circ}$ with the horizontal line. As per the rule:

If $0 \leq$ available water $<S 1$, number of turbines to be operated is 0 ;
If $S 1 \leq$ available water $<S 2$, number of

turbines to be operated is 1 ;

If $S 2 \leq$ available water $<S 3$, number of

turbines to be operated is 2 ; and

If $S 3 \leq$ available water, number of

turbines to be operated is 3 .

Figure 1 shows that the release is to be decreased as the available water increases, which is indicated by the falling curves between the points ( $\left.\mathrm{P} 1, \mathrm{P} 1^{\prime}\right)$, (P2, P2'), and (P3, P3'). When the available-water reaches the full reservoir capacity, the head availability cannot increase further. Thus, at this level, the release becomes constant irrespective of available water. Thus, in the release rule at $K$ in the $x$-axis, the rule curve becomes horizontal.

So far, the values $S 1, S 2$, and $S 3$ are described as the minimum available storage levels at which 1 , 2 , and 3 turbines can be used respectively; however, the trigger values can be set more than these minimum values. When the reservoir is operated using the minimum trigger values, the operation is named Standard Operation Policy-Power $\left(\mathrm{SOP}_{P}\right)$. As explained in the earlier paragraphs, the $\operatorname{SOP}_{P}$ is different from SOP used for operation of reservoirs of other purposes. According to $\mathrm{SOP}_{P}$, if sufficient water is available to operate $n$ number of turbines (at their full loading condition), they will be operated (at their full loading condition). Shifting trigger to a higher value implies preserving some water for future use, which is nothing but hedging. Considering hedging policy, finding the trigger values to maximize the benefits is an optimization problem, which is attempted in this study. The objective of this study is to demonstrate the optimization of the above-explained hed ging rule for maximizing the total power production with constraints on reliability through a case study of 
Indirasagar Reservoir in India. Further, three different optimization algorithms, which are popular and seem to be more promising, are utilized and the comparison of their efficiencies is presented.

\section{Optimization algorithms}

Optimization algorithms that mimic the natural happenings are gaining importance as they prove to be efficient. Evolution mimicry and swarm intelligence mimicry are very popular now. Evolution algorithms like Genetic Algorithm (GA) imitate the natural adaptation process. The favorable traits in the chromosomes are carried to the successive generations by combination and mutual transfer of chromosomal material during breeding and random mutation. Swarm algorithms imitate the behavior of social animals (ant, fish, bee, frog, and bird) in sharing the tasks like foraging. It has been observed that the knowledge gained by interactions among the members of the swarm along with experience of individual members optimizes the operations. In the recent years, plenty of new algorithms have been proposed and many have been applied in the civil engineering and water management fields [22-26]. Many variations and hybrids of these algorithms have also been described in the literature. Though the scope of this paper is not to evaluate them all, an attempt is made to compare the effectiveness of a few popularly used algorithms for getting a guideline on the direction of future research. Particle Swarm Algorithm, Ant Colony Algorithm, and Artificial Bee Colony (ABC) algorithm are few important swarm intelligence algorithms. Among them, ABC algorithm is relatively newer, which has been claimed to be one of the efficient algorithms [27,28]. Further, Imperialist Competitive Algorithm (ICA) is also claimed to be a promising algorithm. Hence, the basic GA, ABC, and ICA algorithm are used for optimizing the hedging rules and the comparisons of optimization algorithms are presented in this paper.

In this study, a bi-level simulation-optimization approach is used. The simulation model is a monthly mass-balance model that uses the hedging parameters and finds the performance by operating through 384 months. The parameters of hedging rules are taken as decision variables. The simulation model is used as a sub-model of an optimization model for optimizing the hedging parameters and is called repeatedly by the optimization algorithm. The optimization model generates values for hedging rule parameters or decision variables (individual in GA, location of honey in $\mathrm{ABC}$, location of a country in ICA) and passes them to the simulation model for (fitness in GA, quality of source in $\mathrm{ABC}$, cost in ICA) evaluation. The performance is passed back to the optimization model to adjust the values of hedging parameters for improving the performance. This process is repeated until satisfying the stopping criteria.

\subsection{Genetic algorithm}

A simple GA is used in this study. Descriptions of GA can be found in Deb [29]. GA is a population based optimization algorithm in which each individual represents a solution. The initial population is generated randomly. GA involves coding of decision variables, fitness evaluation of solutions, and genetic operations for finding new solutions. Binary coding is used in this study for representing decision variables. Fitness of solutions is evolved using the objective function and violation of constraints. When a constraint is violated, a big penalty is added with objective function value so as to make it less fit. With the known fitness values, using the GA operators crossover and mutation, a new population is generated. GA has been used for reservoir operation by many studies, while few have applied it for optimizing operations of hydropower reservoir [30,31].

\subsection{Artificial Bee Colony (ABC) algorithm}

ABC algorithm has been used since 2005 and is a swarm intelligence based optimization algorithm. This algorithm is briefly explained below and detailed descriptions and applications can be found elsewhere [3234]. In real bee colony, the foraging is performed by bees that are classified as scout bees, employed bees, and onlooker bees. First, the scout bees explore the honey source by random search. After a period, scout bees return to the hive with the honey collected and perform a dance called waggle dance. The bees communicate the information (amount of honey, direction, and distance of source) about the honey source they have identified through the waggle dance to the onlooker bees waiting in the dance area. Some of the onlooker bees select to explore the neighborhood of a good honey source indicated in the waggle dance based on its quality. By waggle dance, the bees that find good source attract onlookers and go back to the neighborhood of the same source accompanied by the attracted onlookers. The number of attracted onlookers depends on the quality of the source identified, which is indicated by the waggle dance. A bee, which goes to the neighborhood of the source already identified by it, is called an employed bee. A bee returns and stays in the hive as a scout bee after exhausting the search in an area. Some of the scout bees decide to perform random search. These processes continue repeatedly.

The location of honey represents a solution (values for decision variables) to the optimization problem. The quality of the location (the amount of honey) represents the fitness of the solution. The fitness is calculated using objective function equation. The present study is aimed to maximize the total energy 
generation as explained in Eq. (6). The more the total energy generation, the higher is the fitness. The location (decision vector value) considered by the $i$ th artificial bee is denoted by $z_{i}$. Each location or decision vector has $D$ number of values representing the optimization parameters and each component of $z_{i}$ is represented by $z_{i, j}$. The artificial onlooker bee chooses a honey source depending on the relative fitness, which is calculated as follows:

$$
r_{i}=\frac{f_{i}}{\sum_{n=1}^{N} f_{n}},
$$

where $N$ is the number of employed artificial bees or number of honey sources and $f_{i}$ is the fitness of a location or solution. The new search location for an artificial bee based on its previous memory is calculated as follows:

$$
z_{i, j}^{\text {new }}=z_{i, j}^{\text {old }}+\operatorname{Rand}_{i, j}\left(z_{i, j}^{\text {old }}-z_{k, j}^{\text {old }}\right),
$$

where $i \in(1,2, \ldots, N), k \in(1,2, \ldots, N), j \in(1,2, \ldots, D)$, $k \neq i$, and $\operatorname{Rand}_{i, j}$ are random numbers between -1 and 1. In this study, $k$ is selected randomly. A more detailed explanation of the algorithm can be found elsewhere [32-34].

\subsection{Imperialist Competitive Algorithm (ICA)}

ICA was first reported in 2007 and is a socio-politically motivated optimization algorithm. This algorithm is briefly explained below and detailed descriptions and applications can be found in [35-39]. In this algorithm, the number of countries is considered to form a population and the optimization process starts with a random initial population. The countries are categorized into either colony-country or imperialiststate. An imperialist-state and its colonies together form an empire. The population is initially assumed to have few empires. ICA works based on imperialistic competition among these empires. In the process of competition, weak empires deteriorate and strong ones increase the number of colonies attached to them.

As in the $\mathrm{ABC}$, the location of a country decides the cost; location is a set of values for decision variables; however, the lower the cost, the more powerful is the country. At the beginning, location of each country is set randomly. The number of countries to be considered (population size) and the number of empires are arbitrarily decided. The most powerful countries are selected as imperialistic-states and other countries are considered as colonies. The number of colony countries to be attached to an imperialistic-state is decided based on the relative power of the imperialistic-state. Once the number of colony countries is decided, they are randomly chosen and attached to the imperialisticstates.

In the iterations for optimization, each colony country moves toward the imperialist-state by a random value. If the movement is too small, too many explorations are necessary. If the movement takes the colony very close to imperialistic-state, it reduces the search ability. If the movement takes the colony too far from the imperialistic-state, divergence may occur. In the new position, if a colony is more powerful than its imperialistic-state, the colony becomes imperialisticstate and imperialistic-state becomes a colony.

All empires try to bring colonies under their control from other empires. This competition reduces the power of few empires and, at the same time, increases the power of other empires. The weakest colony of the weakest empire is taken for transfer of control. Calculation of empire's total power is given below:

$$
\mathrm{TP}_{j}=\mathrm{CI}_{j}+R_{1} \frac{\sum_{i=1}^{n c_{j}} C_{j, i}}{n c_{j}},
$$

where $\mathrm{TP}_{j}$ is total power of the empire $j, \mathrm{CI}_{j}$ is the cost of imperialistic-state in the empire $j, R_{1}$ is a random number (taken as 0.1 ), $n c_{j}$ is number of colonies in the empire $j$, and $C_{j, i}$ is cost of colony $i$ in the $j$ th empire. Probability of taking the weakest colony by an empire is evaluated based on the relative total power among the empires. The random number generated and the probability affect the control transfer. In the process of imperialistic competition and control transfer, an empire subsides when it drops off all its colonies and the imperialistic-state becomes a colony. Revolution, similar to mutation process in GA, is also applied to increase the exploration and prevent convergence on local minima. The above-described process of ICA, the collapsed empires, and colonies move toward the imperialistic-state and, finally, there will be only one location. In this situation, all the colonies and imperialistic-state have the same power as they are all in the same location.

\section{Indirasagar reservoir system}

Indirasagar reservoir is located at Narmada River in India at $22^{\circ} 17^{\prime} 00^{\prime \prime} \mathrm{N}, 76^{\circ} 28^{\prime} 00^{\prime \prime} \mathrm{E}$. The reservoir is built for the main purpose of hydropower generation. The reservoir has a storage capacity of 12,212 million $\mathrm{m}^{3}$ at a full reservoir level of $262.13 \mathrm{~m}$ and its capacity at minimum draw down level of $237.70 \mathrm{~m}$ is 1357 million $\mathrm{m}^{3}$. The powerhouse level is $196.6 \mathrm{~m}$ and there are 8 turbines with a power generation capacity of $125 \mathrm{MW}$ each. The overall efficiency of the turbines is $85 \%$.

Thirty-two years of inflow into the reservoir is used in this study. Monthly period is used and, hence, for the 32 years, the total number of periods is 384 . The evaporation loss is calculated by multiplying water spread area and rate of evaporation. In a monthly step, the average storage ((beginning storage + end storage)/2) is worked and the corresponding water 
spread area is found using the storage-water spread area relationship shown below:

$$
\mathrm{WSA}=\left(-2 \times 10^{-6} \times S^{2}\right)+(0.0972 \times S),
$$

where $S$ is storage in $10^{6} \mathrm{~m}^{3}$ and WSA is water spread area in $10^{6} \mathrm{~m}^{2}$.

\subsection{Objective function and constraints}

The objective is to maximize the total energy generation, that is:

\section{$\operatorname{Max} \mathrm{TE}$}

where $\mathrm{TE}=\sum_{\mathrm{mon}=1}^{384} E_{\mathrm{mon}}=\sum_{\mathrm{mon}=1}^{384} c \times R_{\mathrm{mon}} \times H_{\mathrm{mon}}$, $E_{\text {mon }}$ is the energy produced in month mon; $c$ is energy production coefficient, which includes overall turbine efficiency of $85 \% ; R_{\text {mon }}$ is the release made for power generation alone; Spill mon is the variable; and $H_{\text {mon }}$ is the average head of water available for power production. The flow continuity constraint, and the minimum and maximum storage constraints are used as follows:

$$
\begin{gathered}
S_{\text {mon }+1}=S_{\text {mon }}+I_{\text {mon }}-E v p_{\text {mon }}-R_{\text {mon }} \\
\quad-\text { Spill }_{\text {mon }}, \quad \forall \text { mon } \\
S^{\text {min }} \leq S_{\text {mon }} \leq S^{\text {max }}, \quad \forall \text { mon. }
\end{gathered}
$$

$\forall$ mon is used as a notation for all months.

There are 8 turbines in the system and each has a capacity of $125 \mathrm{MW}$. In this study, the turbines are considered for either full loading or no-loading conditions. Hence, power production for a month $\left(P_{\text {mon }}\right)$ can be any one from the set of $(0,125,250$, $375,500,625,750,875$ and $1000 \mathrm{MW})$ :

$$
\begin{aligned}
& P_{\text {mon }} \in(0,125,250,375,500,625,750,875, \\
& \text { and } 1000 \mathrm{MW}), \quad \forall \text { mon. }
\end{aligned}
$$

Reliability can be defined as the probability of a system to be in success state. A minimum power production $P_{\text {min }}$ is expected at all times. If $P_{\text {mon }} \geq P_{\text {min }}$, then the month is considered successful and otherwise, the month is considered to be a 'failure' month. The optimization process is set to allow a certain number of 'failures' through a reliability constraint. A reliability index is defined as follows:

$$
\begin{aligned}
\text { Reliability index } & =\mathrm{RI} \\
& =\left(1-\frac{\text { Number of failures }}{\text { Number months }}\right) \times 100 .
\end{aligned}
$$

Hence, a constraint is adopted as given below:

$$
\mathrm{RI} \geq \mathrm{RI}_{\min } .
$$

In case of $\mathrm{RI}<\mathrm{RI}_{\min }$, a big penalty $(-3841000)$ is added with objective function value so that the solution violating this constraint is forced to be ineligible for optimum solution.

The economic impact due to continuous failure periods is more critical than the intermittent failures. Hence, with the total number of failure periods remaining fixed, continuous failures are undesirable compared to intermittent failures [40]. The characteristic of recovery from failure to success is generally provided by a special reliability function, called resilience. The ability of the system to recover from failure state to success state will be defined as resilience [40]. In this study, both reliability and resilience constraints are used for finding the optimal operation rules. Once the system performance enters a failure mode, until it recovers to a success mode, the whole duration is considered as a failure event.

To provide a good measure of resilience, the following two resilience indicators are used. Within the operation horizon (384 months), Maximum Number of Consecutive Failure months (MNCF) is taken as a resilience indicator. However, using this resilience indicator alone may have some drawbacks [40]. Hence, another resilience indicator is also considered based on the mean recovery time from a failure event or the mean duration of a failure event or Mean Down Time (MDT). The MNCF and MDT are constrained by user specified $\mathrm{MNCF}_{\max }$ and $\mathrm{MDT}_{\max }$. Thus, the constraints are written as:

$$
\begin{aligned}
& \mathrm{MNCF} \leq \mathrm{MNCF}_{\max } \\
& \mathrm{MDT} \leq \mathrm{MDT}_{\max } .
\end{aligned}
$$

In this study, if $\mathrm{MNCF}>\mathrm{MNCF}_{\max }$ or $\mathrm{MDT}>$ $\mathrm{MDT}_{\text {max }}$ or MNCF > $\mathrm{MNCF}_{\text {max }}$ and MDT > $\mathrm{MDT}_{\text {max }}$, a big penalty $(-3841000)$ is added with objective function value so that the solution is forced to be ineligible for optimum solution. Apart from the above constraints, the set of hedging rules similar to Eq. (1) is used. Application of hedging rule is analyzed through three different cases.

\subsection{Hedging rules}

In the first case, a single set of hedging rules is applied for all the 12 months of a year. Six different power production options $(0,125,250,500,750$, and $1000 \mathrm{MW}$ ) are considered. To describe the optimum operation rules, five storage levels or decision variables ( $S 1$ to $S 5)$ are to be determined. Similar to Eq. (1), five different storage levels and six (including zero) different power production options are considered.

In the second case, a year is divided into two seasons of six months each (July to December and January to June). For each season, a set of hedging rules is used. In each season, six different power production 
options are considered. The power production options considered for the first and second seasons are $(0,125$, $500,625,750$, and $1000 \mathrm{MW})$ and $(0,125,250,375$, 500 , and $625 \mathrm{MW}$ ), respectively. In the first season, the inflows are generally more and, hence, higher power production options are considered. In this case, there are 10 decision variables ( $S 1$ to $S 5$ for season 1 ; and $S 6$ to $S 10$ for season 2), which are to be found by optimization.

In the third case, a year is divided into three seasons based on the inflow (July to Septemeber, October to December, and January to June). Generally, the first season gets more inflows (mean $=6793$ million $\left.\mathrm{m}^{3} / \mathrm{mon}\right)$ and the options considered are $(0,125,500$, $625,750$, and $1000 \mathrm{MW})$. The second season gets moderate inflows $\left(\right.$ mean $=1739$ million $\mathrm{m}^{3} /$ mon $)$ and the power production options considered are $(0,125,250$, $500,750$, and $1000 \mathrm{MW})$. The third season gets less inflows $\left(\right.$ mean $=928$ million $\left.\mathrm{m}^{3} / \mathrm{mon}\right)$ and the power production options considered are $(0,125,250,375$, 500 , and $625 \mathrm{MW}$ ), respectively. Hence, considering all the three seasons, the number of decision variables is 15 ( $S 1$ to $S 5$ for season 1; $S 6$ to $S 10$ for season 2; and $S 11$ to $S 15$ for season 3 ), which are to be found by optimization.

\section{Results and discussions}

Though the reservoir has eight turbines, the study reveals that the reliability index cannot be $100 \%$ even for a single turbine operation (125 MW) and, hence,
$P_{\text {min }}$ is taken as $125 \mathrm{MW}$. The minimum available storage values required for operating the turbines are listed in Table 1. The minimum available storage values for each power production level are determined based on the relationship, $P \propto Q H$. For example, for a production of $125 \mathrm{MW}$, the 'minimum available storage' $\left(=1022\right.$ million $\left.\mathrm{m}^{3}\right)$ is an available storage that is to be fully released such that this release with a mean head (of initial and final heads) could just generate $125 \mathrm{MW}$. However, for an available storage of 5000 million $\mathrm{m}^{3}$, a release of 751 million $\mathrm{m}^{3}$ is sufficient to produce $125 \mathrm{MW}$ as the mean head is more. Based on the Indirasagar reservoir hydraulic data, relationships between 'available storage' and release are evaluated for various power production levels using curve fitting, which are presented in Table 1 . The 'minimum available storage values required' and the 'release equations' given in Table 1 form the $\operatorname{SOP}_{P}$. The results of $\mathrm{SOP}_{P}$, when applied for Cases 1, 2, and 3 , are presented in Table 2 .

When the limiting values in the Constraints (12)(14) are modified, different optimal results are obtained. The optimum results obtained through hedging are presented in Table 3 for all the three cases. Among the three cases, Case 1 produces the lowest total energy with the highest RI. Case 3 produces maximum total energy while not compromising much on RI. Further, the total spill is also low in Case 3. MNCF does not play significant role to differentiate among the three cases. Among the three cases, Case 3 is expected to perform best as the number of rules used for the

Table 1. Minimum requirement of the available storage for operating turbines.

\begin{tabular}{|c|c|c|c|}
\hline $\begin{array}{c}\text { Number of } \\
\text { turbines }\end{array}$ & $\begin{array}{c}\text { Power } \\
\text { generation } \\
(\mathrm{MW})\end{array}$ & $\begin{array}{c}\text { Min. available } \\
\text { storage } \\
\text { required } \\
\left(10^{6} \mathrm{~m}^{3}\right)\end{array}$ & Release equation $(R)\left(10^{6} \mathrm{~m}^{3}\right)$ \\
\hline 1 & 125 & 1022 & $-307.8 S^{3} \times 10^{-12}+1035.6 S^{2} \times 10^{-8}-1197.6 S \times 10^{-4}+1128$ \\
\hline 2 & 250 & 1955 & $-684.6 S^{3} \times 10^{-12}+2320.8 S^{2} \times 10^{-8}-2712.0 S \times 10^{-4}+2395.8$ \\
\hline 3 & 375 & 2827 & $-1083.6 S^{3} \times 10^{-12}+3763.8 S^{2} \times 10^{-8}-4506.6 S \times 10^{-4}+3815.4$ \\
\hline 4 & 500 & 3657 & $-1488.0 S^{3} \times 10^{-12}+5353.2 S^{2} \times 10^{-8}-6631.86 S \times 10^{-4}+5433$ \\
\hline 5 & 625 & 4456 & $-2250.0 S^{3} \times 10^{-12}+7780.8 S^{2} \times 10^{-8}-9411.0 S \times 10^{-4}+7250.4$ \\
\hline 6 & 750 & 5234 & $-3117.0 S^{3} \times 10^{-12}+11160.0 S^{2} \times 10^{-8}-13797.6 S \times 10^{-4}+9837.6$ \\
\hline 7 & 875 & 5997 & $-4306.8 S^{3} \times 10^{-12}+15496.2 S^{2} \times 10^{-8}-19249.8 S \times 10^{-4}+12889.2$ \\
\hline 8 & 1000 & 6751 & $-5584.2 S^{3} \times 10^{-12}+20494.8 S^{2} \times 10^{-8}-25917.0 S \times 10^{-4}+16620.0$ \\
\hline
\end{tabular}

Table 2. Performance of $\mathrm{SOP}_{P}$ for all cases.

\begin{tabular}{ccccccc}
\hline Case & RI (\%) & $\begin{array}{c}\text { No. of times } \\
\text { zero power } \\
\text { is produced }\end{array}$ & MNCF & MDT & $\begin{array}{c}\text { Energy production } \\
\left(\mathbf{T W}-\mathbf{h}^{*}\right)\end{array}$ & $\begin{array}{c}\text { Spill } \\
\left(\mathbf{1 0}^{\mathbf{6}} \mathbf{~ m}^{\mathbf{3}}\right)\end{array}$ \\
\hline 1 & 84.89 & 58 & 2 & 1.18 & 112.07 & 56965 \\
2 & 85.93 & 54 & 3 & 1.17 & 112.25 & 61164 \\
3 & 85.42 & 56 & 3 & 1.22 & 111.96 & 62773 \\
\hline
\end{tabular}

( ${ }^{*} 1 \mathrm{TW}-\mathrm{h}=10^{12}$ Watt-hour) 
Table 3. Optimal reservoir operation policies and their performances.

\begin{tabular}{|c|c|c|c|c|c|c|c|c|c|}
\hline Case & & Rule & & RI (\%) & $\begin{array}{l}\text { No. of } \\
\text { times zero } \\
\text { power is } \\
\text { produced }\end{array}$ & MNCF & MDT & $\begin{array}{c}\text { Energy } \\
\text { production } \\
(\mathrm{TW}-\mathbf{h})\end{array}$ & $\begin{array}{c}\text { Spill } \\
\left(10^{6} \mathrm{~m}^{3}\right)\end{array}$ \\
\hline \multirow{6}{*}{1} & Parameter & Parameter & Parameter & \multirow{6}{*}{98.96} & \multirow{6}{*}{4} & \multirow{6}{*}{3} & \multirow{6}{*}{2.00} & \multirow{6}{*}{116.45} & \multirow{6}{*}{95066} \\
\hline & $S 1=1600$ & - & - & & & & & & \\
\hline & $S 2=4400$ & - & - & & & & & & \\
\hline & $S 3=8700$ & - & - & & & & & & \\
\hline & $S 4=9200$ & - & - & & & & & & \\
\hline & $S 5=9500$ & - & - & & & & & & \\
\hline \multirow[t]{5}{*}{2} & $S 1=1600$ & $S 6=2050$ & - & \multirow[t]{5}{*}{97.40} & \multirow[t]{5}{*}{10} & \multirow[t]{5}{*}{5} & \multirow[t]{5}{*}{2.00} & \multirow[t]{5}{*}{116.90} & \multirow[t]{5}{*}{84287} \\
\hline & $S 2=5900$ & $S 7=5050$ & - & & & & & & \\
\hline & $S 3=6000$ & $S 8=9450$ & - & & & & & & \\
\hline & $S 4=9000$ & $S 9=9750$ & - & & & & & & \\
\hline & $S 5=9100$ & $S 10=11350$ & - & & & & & & \\
\hline \multirow[t]{5}{*}{3} & $S 1=2000$ & $S 6=3000$ & $S 11=1250$ & \multirow[t]{5}{*}{96.88} & \multirow[t]{5}{*}{12} & \multirow[t]{5}{*}{3} & \multirow[t]{5}{*}{1.50} & \multirow[t]{5}{*}{117.27} & \multirow[t]{5}{*}{79070} \\
\hline & $S 2=4500$ & $S 7=4500$ & $S 12=4500$ & & & & & & \\
\hline & $S 3=5500$ & $S 8=10000$ & $S 13=5000$ & & & & & & \\
\hline & $S 4=8000$ & $S 9=10500$ & $S 14=8500$ & & & & & & \\
\hline & $S 5=8500$ & $S 10=11000$ & $S 15=9000$ & & & & & & \\
\hline
\end{tabular}

operation is higher. However, only marginal differences could be seen when analyzing the results. It could be seen from Tables 2 and 3 that the percentage of power failure over the operating horizon is higher in $\operatorname{SOP}_{P}$ in all three cases compared to Hedging. The average power failure is $15 \%$ in $\mathrm{SOP}_{P}$, whereas in hedging rule the power failure is only $2 \%$. Total energy production is also higher in the case of hedging. Reliability of the operation is presented in this study through RI. In the case of $\mathrm{SOP}_{P}$, the RI is about $85 \%$, whereas the RI is above $98.96 \%, 97.40 \%$, and $96.88 \%$ in Cases 1,2 , and 3 , respectively. When the total number of failures is very low, a very small higher value of MDT and/or MNCF does not really matter. Decisions based on MDT and MNCF are essential when the RI is not significantly different between different sets of rules, which is not so in the present study. Comparison of $\operatorname{SOP}_{P}$ and hedging rules clearly indicates that: (1) Hedging rules provide better results than $\mathrm{SOP}_{P}$ for both total energy production and RI, and (2) the total spill is higher when hedging is adopted. More spills are expected when hedging is adopted due to the higher trigger values used for hedging rules.

The hedging policy for Case 1 is presented in the graphical form in Figures 2 and 3 . While Figure 2 presents the rules in the form of available-storage versus power production; Figure 3 presents the rules

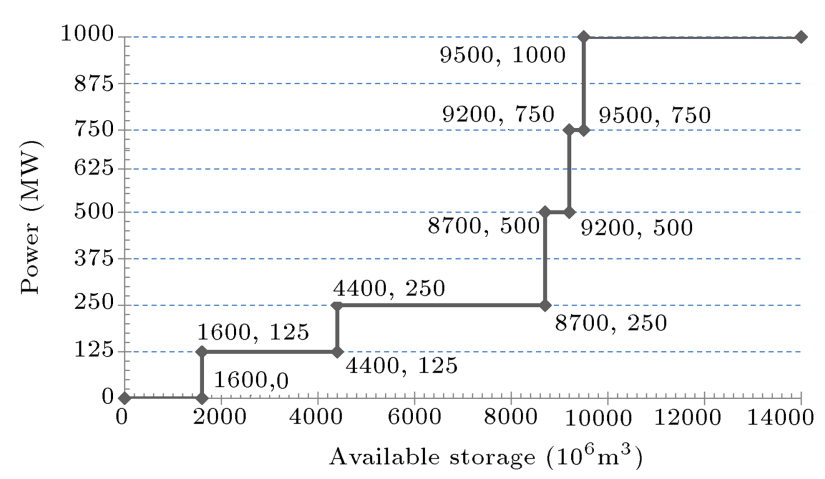

Figure 2. Optimal hedging policy for Case 1 in the form of available-storage versus power production.

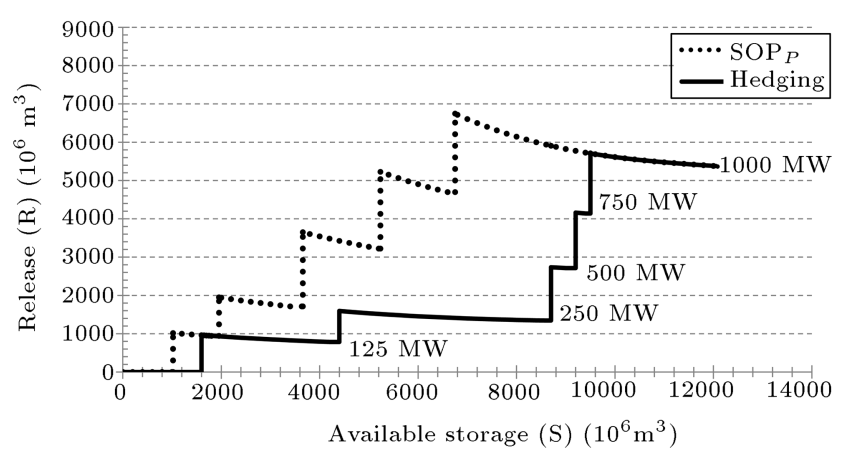

Figure 3. Optimal hedging policy for Case 1 in the form of available-storage versus release. 
Table 4. Comparison of accuracy and number of function-evaluations required by the optimization algorithms.

\begin{tabular}{cccc}
\hline Method & $\begin{array}{c}\text { Number of } \\
\text { decision variables }\end{array}$ & Mean accuracy (\%) & $\begin{array}{c}\text { Mean number of } \\
\text { evaluations of } \\
\text { the simulation }\end{array}$ \\
\hline GA & 5 & 96.3 & 34216 \\
ABC & & 98.1 & 36018 \\
ICA & & 98.4 & 31563 \\
& \multirow{2}{*}{10} & 91.7 & 254016 \\
GA & & 94.5 & 216117 \\
ABC & & 91.8 & 235521 \\
ICA & \multirow{2}{*}{15} & 89.1 & 953921 \\
& & 92.1 & 864270 \\
GA & & 90.3 & 901543 \\
ABC & & & \\
ICA & &
\end{tabular}

in the form of available-storage versus release. Though Figure 2 looks simple, Figure 3 provides additional details on the amount of water to be released and, hence, it is more preferable. The equations for the curves in Figure 3 for various power generation options are given in Table 1. In Figure 3, along with hedging rules, $\mathrm{SOP}_{P}$ is presented. The deviation of heding rules from $\mathrm{SOP}_{P}$ can be observed in Figure 3. The hedging rules adopt a high trigger value of available-storage for all power production levels and the deviations are larger except for $125 \mathrm{MW}$. Optimization of the hedging rules results in storage targets of $1600,4400,8700$, 9200, and 9500 million $\mathrm{m}^{3}$ to produce $125,250,500,750$ and $1000 \mathrm{MW}$, respectively. It can be observed that the incremental storage values for producing higher power gradually decrease, which may be attributed to the relationship between elevations and storage capacity of the reservoir.

\subsection{Comparison of optimization algorithms}

In this study, three different algorithms are used for optimization. In the GA, crossover probability of 0.8 , mutation probability of 0.05 , single point crossover, population size of 100 , and a maximum of 10000 generations are used. For the $\mathrm{ABC}$ algorithm, 50 number of employed bees or honey sources, 45 number of onlooker bees, 5 scout bees, and a maximum of 10000 cycles are considered. In the case of ICA, an initial population of 100 countries, of which the best 9 are imperialists and the remaining 91 are colonies, a maximum of 10000 iterations, and a revolution probability of 0.05 are considered. All these values for different parameters are decided based on few initial trials. It is found that the performance of the algorithms varies with different trials. The initial population and probabilities influence the performance to a great extent. It is found difficult to make generalized comments on the performance based on the experience gained through this study. A more elaborate statistical study with benchmark optimization problems may be more suitable for comparing the algorithms. However, based on this study, it can be concluded that all the three algorithms can be judged as close competitors. The problem size (number of decision variables) could help a little to decide on the performance. All three algorithms have almost the same performance for Case 1 with 5 decision variables. However, when the number of decision variables increases to 10 or $15, \mathrm{ABC}$ algorithm performs slightly better in terms of accuracy and convergence speed, while the GA and ICA perform almost similarly. Out of 30 different trials made with 15 decision variables, $\mathrm{ABC}$ algorithm is better in 11 trials, GA is better in 8 trials, ICA is better in 9 trials, and in 2 trails all the three algorithms perform almost similarly. However, in all the three optimization procedures, the final optimum solutions are obtained by fine tuning through reducing the zone of search in steps. The detailed comparative results of accuracy and mean number of function evaluations of different algorithms are shown in Table 4.

\section{Conclusions}

In this study, hedging was introduced for the operation of a reservoir, which was meant for hydropower generation. Different forms of hedging rules were discussed and a useful form was identified theoretically and demonstrated with case study results. Further, a new form of SOP was also proposed in this study, especially for hydropower operation of reservoir. The results proved the superiority of hedging rules over $\mathrm{SOP}_{P}$. When the number of decision variables increased, though the reliability was did not decrease much, the produced total energy increased and, fur- 
ther, the spill was reduced significantly. In contrast to hedging rule performance, while operating with $\mathrm{SOP}_{P}$, spill increased $(10.20 \%)$ with the increase in decision variables. These indicate the advantages of the hedging rules. The results reported in this paper are specific to the case study. Though similar results may be expected in other cases, for generalization of the conclusions, more number of similar studies need to be performed. In this work, the planning model was optimized with 5 , 10 , and 15 numbers of decision variables. The numbers of decision variables were decided based on the inflow variability. However, for real-time operation model or more detailed planning model, the optimization will become more complex and pose a challenge for many optimization algorithms. The hedging rules were optimized using GA, ABC, and ICA algorithms. The experience could not allow to conclude superiority of any one algorithm. ABC algorithm performed slightly better for larger optimization problems, but it has to be analyzed and justified further with different problems. However, it can be concluded that a more detailed statistical analysis may be required to identify the performance of these algorithms.

\section{References}

1. Draper, A.J. and Lund, J.R. "Optimal hedging and carryover storage value", J. Water Resour. Plan. Manag., 130(1), pp. 83-87 (2004).

2. Bayazit, M. and Unal, E. "Effects of hedging on reservoir performance", Water Resour. Res., 26(4), pp. 713-719 (1990).

3. Shih, J.S. and ReVelle, C. "Water-supply operations during drought: Continuous hedging rule", J. Water Resour. Plan. Manag., 120(5), pp. 613-629 (1994).

4. Srinivasan, K. and Philipose, M.C. "Evaluation and selection of hedging policies using stochastic reservoir simulation", Water Resour. Manag., 10(3), pp. 163188 (1996).

5. Srinivasan, K. and Philipose, M.C. "Effect of hedging on over-year reservoir performance", Water Resour. Manag., 12(2), pp. 95-120 (1998).

6. Neelakantan, T.R. and Pundarikanthan, N.V. "Hedging rule optimization for water supply reservoirs system", Water Resour. Manag., 13, pp. 409-426 (1999).

7. Neelakantan, T.R. and Pundarikanthan, N.V. "Neural network-based simulation-optimization model for reservoir operation", J. Water Resour. Plan. Manag., 126(2), pp. 57-64 (2000).

8. Shiau, J.T. "Optimization of reservoir hedging rules using multiobjective GA", J. Water Resour. Plan. Manag., 135(5), pp. 355-363 (2009).

9. Shiau, J.T. "Analytical optimal hedging with explicit incorporation of reservoir release and carryover storage targets", Water Resour. Res., 47(1), W01515 (2011).
10. Bower, B.T., Hufschmidt, M.M. and Reedy, W.W. "Operating procedures: Their role in the design of water-resources systems by simulation analyses, in design of water-resource systems", Edited by A. Maass et al., pp. 443-458, Harvard Univ. Press, Cambridge, Mass (1962).

11. Hashimoto, T., Stedinger, J.R. and Loucks, D.P. "Reliability, resiliency and vulnerability criteria for water resources system performance evaluation", Water Resour. Res., 18(1), pp. 14-20 (1982)

12. Moy, W.S., Cohon, J.L. and ReVelle, C.S. "A programming model for analysis of reliability, resilience, and vulnerability of a water supply reservoir", Water Resources Research, 22(4), pp. 489-498 (1986).

13. Shih, J.S and ReVelle, C. "Water supply operations during drought: A discrete hedging rule", European Journal of Operational Research, 82, pp. 163-175 (1995).

14. Tu, M.-Y., Hsu, N.-S., Tsai, F.T.-C. and Yeh, W.W.G. "Optimization of hedging rules for reservoir operations", J. Water Resour. Plan. Manag., 134(1), pp. 3-13 (2008).

15. Reis, L.F.R., Bessler, F.T., Walters, G.A. and Savic, D. "Water supply reservoir operation by combined GA-linear programming approach", Water Resour. Manag., 20(2), pp. 227-255 (2006).

16. Shiau, J.T. "Water release policy effects on the shortage characteristics for the Shihmen reservoir system", Water Resour. Manag., 17(6), pp. 463-480 (2003).

17. Shiau, J.T. and Lee, H.C. "Derivation of optimal hedging rules for a water-supply reservoir through compromise programming", Water Resour. Manag., 19(2), pp. 111-132 (2005).

18. Karamouz, M. and Araghinejad, S. "Drought mitigation through long-term operation of reservoirs: Case study", Journal of Irrigation and Drainage Engineering, 134(4), pp. 471-478 (2008).

19. Celeste, A.B. and Billib, M. "The role of spill and evaporation in reservoir optimization models", Water Resour. Manag., 24(4), pp. 617-628 (2010).

20. Karamouz, M., Imen, S. and Nazif, S. "Development of a demand driven hydro-climatic model for drought planning", Water Resour. Manag., 26(2), pp. 329-357 (2012).

21. Zeng, Y., Wu, X., Cheng, C. and Wang, Y. "Chanceconstrained optimal hedging rule for cascade hydropower reservoirs", J. Water Resour. Plan. Manag., 140(7), 04014010 (2014).

22. Tahershamsi, A., Kaveh, A., Sheikholeslami, R. and Talatahari, S. "Big bang-big crunch algorithm for least-cost design of water distribution systems", International Journal of Optimization in Civil Engineering, 2(1), pp. 70-79 (2012).

23. Kaveh, A., Ahmadi, B., Shokohi, F. and Bohlooli, N. "Simultaneous analysis, design and optimization of water distribution systems using supervised charged system search", International Journal of Optimization in Civil Engineering, 3(1), pp. 37-55 (2013). 
24. Sheikholeslami, R., Kaveh, A., Tahershamsi, A. and Talatahari, S. "Application of charged system search algorithm to water distribution networks optimization", International Journal of Optimization in Civil Engineering, 4(1), pp. 41-58 (2014).

25. Tahershamsi, A., Kaveh, A., Sheikholeslami, R. and Kazemzadeh Azad, S. "An improved firefly algorithm with harmony search scheme for optimization of water distribution systems", Scientia Iranica, 21(5), pp. 1591-1607 (2014).

26. Kaveh, A., Shokouhi, F. and Ahmadi, B. "Analysis and design of water distribution systems via colliding bodies optimization", International Journal of Optimization in Civil Engineering, 4(2), pp. 165-185 (2014).

27. Karaboga, D. and Basturk, B. " A comparative study of artificial bee colony algorithm", Applied Mathematics and Computation, 214, pp. 108-132 (2009).

28. Singh, A. "An Artificial Bee Colony algorithm for the leaf-constrained minimum spanning tree problem", Applied Soft Computing, 9(2), pp. 625-631 (2009).

29. Deb, K., Multi-Objective Optimization Using Evolutionary Algorithm, John Wiley and Sons, Ltd (2001)

30. Cheng, C.T., Wang, W.C., Xu, D.M. and Chau, K.W. "Optimizing hydropower reservoir operation using hybrid GA and chaos", Water Resour. Manag., 22(7), pp. 895-909 (2008).

31. Jothiprakash, V. and Arunkumar, R. "Optimization of hydropower reservoir using evolutionary algorithms coupled with chaos", Water Resour. Manag., 27(7) pp. 1963-1979 (2013).

32. Ozkan, C., Kisi, O. and Akay, B. "Neural networks with artificial bee colony algorithm for modeling daily reference evapotranspiration", Irrigation Science, 29(6), pp. 431-441 (2011).

33. Kisi, O., Ozkan, C. and Akay, B. "Modeling dischargesediment relationship using neural networks with artificial bee colony algorithm", Journal of Hydrology, 428-429, pp. 94-103 (2012).

34. Liao, X., Zhou, J., Ouyang, S., Zhang, R. and Zhang, Y. "Multi-objective artificial bee colony algorithm for long-term scheduling of hydropower system: A case study of China", Water Utility Journal, 7, pp. 13-23 (2014).

35. Kaveh, A. and Talatahari, S. "Optimum design of skeletal structures using imperialist competitive algorithm", Computers and Structures, 88(21-22), pp. 1220-1229 (2010).
36. Niknama, T. Fard, E.T., Pourjafarian, N. and Rousta, A. "An efficient hybrid algorithm based on modified imperialist competitive algorithm and $K$-means for data clustering", Engineering Applications of Artificial Intelligence, 24(2), pp. 306-317 (2011).

37. Bagher, M., Zandieh, M. and Farsijani, H. "Balancing of stochastic U-type assembly lines: An imperialist competitive algorithm", International Journal of Advanced Manufacturing Technology, 54(1-4), pp. 271285 (2011).

38. Talatahari, S., Kaveh, A. and Sheikholeslami, R. "Chaotic imperialist competitive algorithm for optimum design of truss structures", Structural and Multidisciplinary Optimization, 46(3), pp. 355-367 (2012).

39. Nazari-shirkouhi, S., Eivazy, H., Ghodsi, R., Rezaie, K. and Atashpaz-Gargari, E. "Solving the integrated product mix-outsourcing problem using the imperialist competitive algorithm", Expert Systems with Applications, 37(12), pp. 7615-7626 (2010).

40. Srinivasan, K., Neelakantan, T.R., Narayan, P.S. and Nagarajukumar, C. "Mixed-integer programming model for reservoir performance optimization", $J$. Water Resour. Plan. Manag., 125(5) pp. 298-301 (1999).

\section{Biographies}

Kandasamy Sasireka obtained her BE degree in Civil Engineering from Bharathidasan University and MTech from National Institute of Technology, Tiruchirappalli, in 1998 and 2003, respectively. She was awarded PhD in 2017 from SASTRA University.

Thurvas Renganathan Neelakantan is a Senior Professor in the Department of Civil Engineering at Kalasalingam University. Earlier he served as faculty member at SASTRA University in India and at University of Kentucky in USA. He received his BE in Civil Engineering from Madurai Kamaraj University, ME in Hydrology and Water Resources Engineering from Anna University, Chennai, and PhD from Anna University, Chennai, in 1991, 1993, and 1998, respectively. His research interests include water resources engineering, management, optimization, neural networks, and environmental modeling. He has published and presented various papers in journals and at conferences in these fields. 